Identifying social indicators for sustainability assessment of CCU technologies: a modified multi-criteria decision making Peer-reviewed author version

RAFIAANI, Parisa; DIKOPOULOU, Zoumpolia; VAN DAEL, Miet; KUPPENS, Tom; AZADI, Hossein; Lebailly, Philippe \& VAN PASSEL, Steven (2020) Identifying social indicators for sustainability assessment of CCU technologies: a modified multi-criteria decision making. In: Social indicators research, 147(1),p. 15-44..

DOI: 10.1007/s11205-019-02154-4

Handle: http://hdl.handle.net/1942/28658 


\title{
Identifying social indicators for sustainability assessment of CCU technologies: a modified multi-criteria decision making
}

\begin{abstract}
Carbon capture and utilization $(\mathrm{CCU})$ technologies capture $\mathrm{CO}_{2}$ waste emissions and utilize them to generate new products (such as fuels, chemicals, and materials) with various environmental, economic, and social opportunities. As most of these CCU technologies are in the R\&D stage, their technical and economic viability are examined with less attention to the social aspect which is an important pillar for a holistic sustainability assessment. The lack of systematic social impact research is mainly due to the difficulty of identifying and quantifying social aspects through the entire life cycle of products. We will fill this gap for CCU technologies and identify the main social indicators. A multi-criteria decision making tool: TOPSIS (technique for order of preference by similarity to ideal solution) was applied to empirically determine which indicators are more relevant for assessing the social impact of a company operating CCU activities within a European context. First, seeing that social impact categories are linked to key stakeholder groups, we considered workers, consumers, and local communities as relevant stakeholders. Second, the main social impact categories and their potential performance indicators associated to each group of stakeholders were listed using the United Nations Environment Program/Society of Environmental Toxicology and Chemistry (UNEP/SETAC) guidelines. In the third step, an online questionnaire was distributed to identify the main social categories and indicators for CCU, to which 33 European CCU experts responded. Finally, a modified TOPSIS was applied to rank the indicators based on their relevance. We found that the indicators related to "end of life responsibility" and "transparency" within a CCU company achieved the highest rank affecting the consumers group, whereas "fair salary" and "equal opportunities/discriminations" were determined as the most relevant impact categories for the workers. For the local community group, "secure living conditions" and "local employment" received the highest priority from the experts' point of view. Furthermore, "health and safety" considerations were identified as one of the most important criteria affecting all three groups of stakeholders. The ranking list of the main social indicators identified in our study provides the basis for the next steps in the social sustainability assessment of CCU technologies; that is, data collection and impact assessment. Our outcomes can also be used to inform the producers regarding the most and least relevant social aspects of CCU so that the potential social impacts caused by their production activities can be improved or prevented.
\end{abstract}

Keywords: sustainability assessment, $\mathrm{CO}_{2}$ emissions, social indicator, SLCA, TOPSIS, CCU.

\section{Introduction}

Global warming is currently a major societal concern, resulting mainly from carbon dioxide $\left(\mathrm{CO}_{2}\right)$ emissions. One possible strategy for mitigating climate change is the reuse of waste $\mathrm{CO}_{2}$, as feedstock for plastics, fuels and chemical production also known as carbon capture and utilization" (CCU) (Klankermayer and Leitner 2015). CCU can also assist in energy transformation by making energy storage through power-to-liquid/gas approaches and play an important role in a circular economy by changing waste emissions to a valuable resource (Bruhn et al. 2016). The potential advantages of applying CCU innovative technologies mainly refer to the resource efficiency, energy and resource security, and their potential economic and social profits. Table 1 demonstrates the technology readiness level (TRL) of a set of CCU technologies. TRL is a systematic measurement tool that makes it possible to evaluate the 
maturity level of a specific technology as well as making a solid comparison of maturity levels among various types of technology (Bocin-Dumitriu et al. 2013). The TRLs are the initial action to locate the technology activity throughout the innovation procedure including 9 levels of development from the lab scale (at TRL 2 and 3) to the full-scale (at TRL 7 and beyond) where the technology has developed into a system applied successfully in its real operating context (Rubin et al. 2012). The TRL is a practical evaluation tool to identify the technological or commercial readiness of technologies and thus is applicable for CCU technologies (BocinDumitriu et al. 2013) which are at low TRL (Table 1) and mainly in the research and development phase (Wilson et al. 2015). Each TRL level is associated with a specific data availability level and accuracy of the given information (Thomassen et al. 2018). Considering the lower maturity levels of CCU technologies, it is not possible to gather detailed data on all sustainability concerns connected to CCU specifically from the social dimension. This can be tackled by focusing on the aspects that experts consider the most relevant. This information informs policy makers and technology developers regarding the most and least relevant social aspects of CCU that should be taken into account when further developing these technologies to higher TRLs. As such, the potential social impacts caused by their production activities can be improved or prevented. By at least focusing on the most relevant impacts, we also take into account the advice of several researchers such as Hardisky et al. (2011), who stated that the overall life cycle cost of innovative technologies must be taken into account; in other words, the total social, economic and environmental benefits of technologies, as well as their potential social costs and environmental risks.

\section{[Insert Table 1]}

Importantly, for technologies at a larger scale with a long-term development procedure and with which consumers and investors are not familiar, it is important to consider potential social (both positive and negative) aspects at the early steps of the development process in order to adjust the technical development accordingly (Kowalewski et al. 2012). Moreover, considering that awareness regarding CCU is very limited among public and various involved stakeholders, it is also important to not only identify potential social impacts that are necessary for an effective adoption of innovative technologies (Rogers 2003), but also to take them into account as a basis for policy making. The investigation of societal stakeholders' perceptions, with a focus on government, academia and industrial stakeholders, regarding the potential social impacts through life cycle phases, will help in designing information strategies (Zaunbrecher and Ziefle 2016) along with an on-time participatory policy effort. In this regard, relevant social impact evaluation studies are required for shaping detailed plans and connecting and improving public acceptance with expert knowledge to determine positive and negative viewpoints on many aspects related to $\mathrm{CCU}$, aiming to help policy makers plan and apply more appropriate strategies to speed up the expansion of innovative technologies (Ragland et al. 2011; Wassermann et al. 2011). The following section provides an overview of relevant literature, bundling existing knowledge on the social impacts of CCU within the sustainability assessment studies.

\subsection{Literature overview on the social sustainability assessment of $\mathrm{CCU}$}

Most studies have investigated technical, economic (Kuramochi et al. 2011; Jones et al. 2014; Naims, 2016; Pérez-Fortes and Tzimas 2016), and environmental aspects of CCU technologies (see Cuellar-Franca and Azapagi (2015) for a review study on the life cycle environmental impacts of CCU), whereas there is a lack of systematic research on the social part as one of the three pillars of sustainability. There have only been a few studies conducted on public acceptance and perception regarding $\mathrm{CCU}$ technologies, mainly in the UK and Germany 
(Perdan et al. 2017; van Heek et al. 2017; Jones et al. 2017; Jones et al. 2015; Jones et al. 2014). Pieri et al., (2018) conducted a review of around 80 important studies on the sustainability assessment of CCU value chains and they concluded that the social impact evaluation is totally neglected in all of those studies and highlighted the importance of considering the affected stakeholders throughout the value chain and all components of sustainability in the assessment of CCU technologies. Similarly, Zimmermann and Schomacker (2017) conducted a review on 29 publications regarding CCU impact assessments and concluded that there is no social assessment at any TRL of CCU systems. Understanding of the potential social impacts related to $\mathrm{CCU}$ activities and related technologies is still at an early stage and has mainly been generically investigated. To the best of our knowledge, no studies have yet focused on the social impact evaluation of CCU from a life cycle perspective. As Table 1 shows, the use of captured $\mathrm{CO}_{2}$ in methanol synthesis is almost implemented at commercial scale (Quadrelli et al., 2011). However, only techno-economic and environmental assessments (Pérez-Fortes and Tzimas., 2016) have been done for this CCU technology, without any social impact considerations.

Furthermore, there is only a limited perception of how companies understand the relevance of social concerns and what kind of indicators they need to consider that are specifically applicable in decision making (Harms et al. 2013). Kuhnen and Hahn (2017) found that researchers theoretically consider a wide range of sectors for social life cycle assessment (SLCA). However, most of the sectors received less attention regarding empirical studies on SLCA. Besides, due to the inconsistency in indicator lists for SLCA for different sectors, researchers usually utilize various and non-equivalent indicators that they subjectively consider to be most related to the theoretical framework under investigation. Therefore, incomparable outcomes will be the result of social impact evaluation of different systems and product life cycles (Hassini et al. 2012; Rafiaani et al. 2018). Foolmaun and Ramjeeawon (2013) discussed the importance of applying a social impact evaluation, considering that the impact categories and stakeholders associated with a social impact assessment process are not equally relevant. Thus, the relevance level of each social indicator needs to be taken into consideration by calculating their weights (Traverso et al. 2012). Similarly, Manik et al. (2013) recommended the importance of applying a weighting system to impact categories and indicators. Previous studies considered the role of social impact among various systems (Ekener-Petersen and Finnveden 2013; Vinyes et al. 2013), and applied a five-scale measure to calculate the social impacts (Foolmaun and Ramjeeawon 2013), and also conducted a questionnaire survey among the influenced stakeholders to identify the impacts (Aparcana and Salhofer 2013; Manik et al. 2013). Considering that no complete and agreed methodology exists yet, all attempts to improve the application of social impact evaluation from real case studies are appreciated, although in every assessment, special aspects might be covered because of the methodological and practical barriers in social sustainability assessment procedures (Martínez-Blanco et al. 2014). Consequently, there is a need to develop a common priority list of impact categories and indicators for social sustainability assessment of companies performing CCU activities (Zimmermann \& Schomacker 2017) that can facilitate and promote empirical experiences and make it possible to compare between the social sustainability performance of different CCU technologies. The present study addresses this need.

As there are multiple social indicators and stakeholders' opinions, identifying the main social aspects is a multi-criteria decision making issue. Therefore, multi-criteria decision making (MCDM) methodologies have shown the capacity to assist stakeholders to identify and concur on sustainable solutions in a broad range of sectors (Buchholz et al., 2009). MCDM are methodologies to evaluate different alternatives that have multiple assessment points of view and contain a vast range of stakeholders (Gnansounou 2011). Many existing studies have used MCDM to sustainability evaluations of biofuels (Turcksin et al. 2011; Sultana and Kumar 
2012; Scott et al. 2012). These studies have applied MCDM to tackle multi-stakeholder involvement (Buchholz et al. 2009), to determine the best/worse/most sustainable options for bioenergy alternatives (Turcksin et al. 2011; Sultana and Kumar 2012), and to assess the interactions between indicators (Mendoza and Prabhu, 2003). Some authors have provided overviews of the previous MCDM studies within the bioenergy and renewable energy fields (Huang et al. 2011; Wang et al. 2009). In the present study, we apply a MCDM called TOPSIS (Technique for Order of Preference by Similarity to Ideal Solution), which is one of the bestknown MCDM approaches (Onat et al. 2016a) and broadly used in literature to tackle with multi-objective decision making issues in sustainability studies (e.g., Onat et al. 2016b; Streimikiene et al. 2012; Doukas et al. 2010), as well as ranking purposes (e.g., Hasan et al. 2014; Wang 2015). The motivation for selecting TOPSIS ahead of other available MCDM approaches is discussed in more detail in the next section. The results of our study can enable companies and policy makers to pay more attention to the most urgent social areas when developing/implementing CCU at higher TRLs. Moreover, the modified MCDM method for analyzing the results of the survey can be considered as a flexible ranking technique in other research fields aiming to incorporate rating approaches.

The paper is structured as follows: Section 2 provides an overview of the different research steps including the questionnaire design, data collection and analysis techniques. In Section 3 the research outcomes are provided along with a comparison of the differences in values resulting from the modified MCDM with the average rating values of the impact categories and indicators. Section 4 further discusses the results of this study, followed by policy implications of our findings and the general conclusion of our work.

\section{Methodology}

We identified the relevance level of the indicators for measuring the social impacts. First, potential affected stakeholder groups and related social impact categories and their performance indicators are listed using the United Nations Environment Program/Society of Environmental Toxicology and Chemistry (UNEP/SETAC) guidelines (Benoit and Mazijn 2009). The guidelines were developed for the social impact evaluation of companies and products from a life cycle perspective. We use the UNEP/SETAC guidelines as the basis for our analysis because they are considered as a basis for many social life cycle assessment studies and/or for choosing relevant social concerns and their related indicators (Ekener-Petersen and Moberg 2013; Martínez-Blanco et al. 2014). Second, through an online questionnaire survey, CCU experts at a European level were asked to prioritize the impact categories and indicators in terms of their own degree of preference. Later, their responses were converted to numerical values for further analysis using TOPSIS to generate the weights of impact categories and to identify indicators of high importance. Finally, to check the validity of the results, we compared the results of the modified TOPSIS and the MEAN values. Each of these steps are explained in more detail in the following sections.

\subsection{Stakeholder groups, impact categories, and indicators}

In view of the present lack of research into social impacts of $\mathrm{CCU}$, we conducted a survey that aimed to capture experts' opinion on the priority areas of such impacts. Based on the stakeholder categories introduced by UNEP/SETAC (2009) guidelines (Table 2), a company's social performance can be measured in five categories, resulting from company-stakeholder relationships along the life cycle: (i) workers, (ii) the local community, (iii) consumers, (iv) society, and (v) value chain actors. One of the common approaches that is commonly applied by practitioners for choosing the stakeholder groups based on the UNEP/SETAC guidelines is 
to consider only those parts of the life cycle which is directly affected by the company performance (Dreyer et al., 2010). Such an approach is along with Corporate Social Responsibility (CSR) where the conduct of a particular company and its social impact is the main consideration instead of the social impacts of a product along its whole life cycle (performance (Foolmaun and Ramjeeawon 2013). Given the fact that CCU are mostly in lower TRLs, the first three categories (workers, local community, consumers) were found as the main stakeholders impacted along by the companies active in CCU in lower TRLs. These groups are also mostly mentioned in literature (Hossain et al. 2017; Wang et al. 2016) as the main stakeholders affected along the life cycle of a product/industry from the social perspective (Fig. 1). Accordingly, three questionnaires were developed for each mentioned group of stakeholders.

[insert Fig. 1]

[Insert Table 2]

\subsection{Questionnaire design}

An online questionnaire software called 'Qualtrics' was used to distribute the questionnaires in May-July 2017. The first part of the questionnaire was an introduction on CCU and the purpose of conducting this survey study. The second part asked respondents to (i) rate the relevance level of each indicator associated with each impact category, followed by (ii) a question on rating the relevance levels of different impact categories. Third, demographic information (age, gender, country, and education level) was collected, followed by four questions regarding participants' self-reported CCU/social expertise, and their specific experience with CCU activities. A complete version of the questionnaire can be provided by the authors upon request. The respondents assessed each question related to the social impact categories and indicators on a five-item scale that ranged from "not relevant" $(0)$ to "very relevant" (4). We also gave an option of "I do not have an opinion" to the respondents. With this option, respondents will not be forced to give an opinion on a question to which they do not know the answer or do not have a strong opinion about (Poe et al., 1988; Afsordegan et al., 2016). The idea of adding a "I do not have an opinion" to reduce the chance of non-attitude reporting is supported by previous researchers (e.g., Converse \& Presser, 1986; Vaillancourt 1973; Jahoda et al. 1962; Payne 1951). Although there are different arguments regarding inclusion or exclusion of this option in qualitative research (Krosnick et al. 2002), the inclusion of this option was specifically applied to our case due to the innovative nature of the CCU and being at lower TRLs. Experts might not be familiar with some potential social impacts of CCU that are not already present in the society or stakeholders involved. Since "I do not have an opinion" has an important interpretation for the case of CCU, the values related to this option were treated as missing values. Rather than removing values or observations in total, we replaced missing values with the mean of the observed values for each indicator. There have been discussions about the fact that such quick approaches for treating missing values might underestimate variance and bias summary statistics. However, it is also argued that imputing by average "...can only be used when a handful of values are missing" (Zhang 2016; p. 3), as was the case in our study (that is, two values in one out of 16 observations for the consumer group and in two values in two out of nine observations for the local community group). Furthermore, the purpose here was only to rank the indicators and there were no calculations regarding the relationship between indicators that might affect further statistical analysis.

\subsection{Data collection and participants}


In total, $300 \mathrm{CCU}$ experts from all over Europe were identified and contacted via e-mail and a link to the online questionnaire. Four follow-up reminders were sent to participants, every two weeks. The completion of the questionnaire took approximately $15 \mathrm{~min}$. It would have been preferable if only experts familiar with both CCU and SLCA could have been reached. However, considering the early stage of development of CCU there were not so many CCU experts who also have knowledge about (social) life cycle thinking to include in the survey. This was not an issue for our study since the focus of SLCA proposed by UNEP/SETAC (2009) guidelines is placed on the behaviour of companies (Zimmermann and Schomacker (2017) which can be only on one or more phases of the life cycle. Therefore, in the questionnaire, it was not asked from the experts to take the whole life cycle into account but only asked to rate the relevance of the indicators/impact categories for assessing the impact of a company's activities on a specific stakeholder group. Recent studies also used the online survey approach and random assignment of experts to the questionnaires. For instance, Onat et al. (2016b) used experts from sustainability research and alternative vehicles sector to apply TOPSIS for ranking the life cycle sustainability performance of alternative vehicle technologies. Arning et al. (2017) conducted a survey study using an online questionnaire in Germany in order to collect the perception of participants to quantify the correlation between risk perception and CCU product acceptance. Using Qualtrics software, Van Schoubroeck et al., (2019) conducted a Delphi survey for ranking the importance of sustainability indicators from life cycle perspective. They selected the participants based on their expertise in sustainability and biobased chemistry and not specifically LCA experts. Vreys et al. (2019) discussed that other qualitative methods like focus groups and interviews would have been very expensive and time-consuming considering the global spread of CCU experts. Given that, they applied an online survey questionnaire using Qualtrics software for collecting the view of the international CCU experts on the challenges and opportunities of CCU.

Accordingly, a purposive sampling method (Okoli \& Pawlowski 2004) has been applied through which we personally chose the experts as it was important that the participants would encompass a range of experts from various sectors involved in the CCU activities. Accordingly, the list of potential experts for our survey was found mainly through the participant lists of 15 online databases of the The International Conferences on Carbon Dioxide Utilization, as well as other active experts of the CCU companies and researchers who had already published scientific papers about sustainability issues of CCU in international journals. The decision criterion for including the experts was their experience in research and development of CCU from technical and sustainability perspectives (social, techno-economic, and environmental pillars). We randomly assigned experts to rate the relevance of the impact categories and indicators related for one of the three groups (workers, consumers, and local community). In total, 100 questionnaires were distributed to each group, for a total of 300 questionnaires, out of which 33 responses (11 percent) were received between May and July 2017. Among the completed questionnaires, 16, eight, and nine surveys were recorded for consumer, workers, and local community groups, respectively (Table 3). A general concern of web-based questionnaires (also usually referred to as online surveys) is their low response rates in comparison to other survey methods (Monroe and Adams 2012). Although it would have been preferable to have received a higher response rate, in the context of our study the low response rate will not convey representativeness (Cook et al. 2000; Huguenin 2015). For example, studies have already been published in which TOPSIS is applied with only three experts (Onat et al. 2016b; Kaya and Kahraman 2011; Afsordegan et al., 2016). The participants, all of whom were postgraduates, were mainly from academia and industry with expertise in CCU technology development and application (Table 3) and/or expertise in social impact evaluation of innovative technologies. The responding experts were mainly in the middle age group 
(between 40-65). As Table 3 shows, the experts' previous experience in CCU activities was comparatively high, while their social impact evaluation expertise was lower.

[Insert Table 3]

\subsection{Analysis technique: Modified TOPSIS}

TOPSIS is one of the many approaches of MCDM, first introduced by Hwang and Yoon (1981) to solve real-world decision issues. There are some advantages in making it an efficient MCDM methodology, such as less complexity in both data gathering and computation processes, simplicity of use, and understandability of the logical basis of human selection (Velasquez and Hester 2013). Despite the similar limitations of other aggregation methods including possibility of the correlations between criteria and uncertainty in obtaining the weights (Xu et al., 2015), it is highlighted in the literature that TOPSIS has an advantage of avoiding the rank-conflicting difficulties and this is very useful for making decisions when dealing with a complicated important assessment indicator which might be either decreasing or increasing (Hwang \& Yoon, 1981; Hsieh et al., 2006). Similarly, Niero \& Kalbar (2019) found that employing TOPSIS resolves the conflict between the indicators. Wang (2015) also applied TOPSIS to tackle the subjectivity issue in choosing energy indicators. It has been also applied in many sustainability assessment studies dealing with multi-objective decision making issues (e.g., Onat et al. 2016b; Doukas et al. 2010). Streimikiene et al. (2012) discussed that there are many conflicting indicators in selecting sustainable energy options and they referred to TOPSIS as a useful MCDM to tackle this issue. Hasan et al., (2014) employed TOPSIS to rank the priorities of market participants in assessing low emission generation entries. A comprehensive literature study on TOPSIS applications and methodologies has been conducted by Behzadian et al., (2012). Previous studies also compared TOPSIS application with other MCDM methodologies in order to identify the most consistent one and the differences in the final ranking results. Amine et al (2014) used an industrial example for conducting a comparative study between the results of six MCDM methodologies in terms of the consistency of the results, the simplicity of understanding and the adjustment with decision type. They found that the aggregation methods resulted in similar ranking and TOPSIS was the most consistent with decision makers' preferences.

Furthermore, instead of normal average values, using TOPSIS as a ranking method can overcome the problem with ties that are of concern when considering only the average values to rank data. TOPSIS flows from the concept of selected best alternative (or ranking the alternatives) that has the shortest distance from the positive ideal solution (PIS) and the farthest from the negative ideal solution (NIS) in a geometrical (Euclidean) sense. In the present study, since TOPSIS is used to rank indicators based on the weights of the impact categories, we refer to "criteria" as "impact category" and "alternative" as "indicator".

Because every impact category in this survey corresponds to different indicators, TOPSIS was modified to handle the zero values in the initial matrix developed for the calculation process of TOPSIS (Dikopoulou et al. 2015). The modification was done to take into account all indicators simultaneously regarding the distances to both PIS and NIS, which in the present study correspond respectively to the "most relevant indicator" and "least relevant indicator", determined by the participants. The ideal and non-ideal solutions are determined by using a normalized matrix. Next, the Euclidean indicator distances from the PIS and NIS points are calculated and the relative closeness to the PIS is obtained, which is in the range of zero to one.

The main difference between the modified TOPSIS and the conventional TOPSIS is observed in the initial decision matrix (in Step 1 of the calculation process). In conventional TOPSIS, $m$ indicators and $n$ impact categories are used and each value shows the score for each indicator 
with respect to each impact category. However, the modified TOPSIS, contains $m$ indicators and $n$ participants. Each value within the initial matrix indicates the relevance of indicator $A_{i}$ with respect to participant $P_{j}$. In the next steps, the weight of the impact categories was multiplied into the normalized decision matrix to calculate the weighted normalized decision matrix. The steps used in the modified TOPSIS are summarized below.

Step 1: Create the decision matrix $D$ by each participant. Where $A_{i}$ indicates the ith social impact indicator, $i=1,2, \ldots, m ; P_{j}$ signifies the $j t h$ participant, $j=1,2, \ldots, n$, referring to sixteen, eight, and nine participants in the current study for consumer, workers, and local community groups, respectively; $x_{i j}$ represents the performance of the $i t h$ indicator as estimated by the $j t h$ participant, which correspond to an integer in the range 0-4 (Table I).

Table I: Matrix D with size $\mathrm{M}^{*} \mathrm{~N}$

$$
\mathrm{D}=\underset{A_{1}}{A_{2}} \begin{gathered}
A_{2} \\
A_{m}
\end{gathered}\left[\begin{array}{cccc}
P_{1} & P_{2} & \ldots & P_{n} \\
\mathrm{x}_{11} & \mathrm{x}_{12} & \ldots & \mathrm{x}_{1 n} \\
\mathrm{x}_{21} & \mathrm{x}_{22} & \ldots & \mathrm{x}_{2 n} \\
\vdots & \vdots & \ddots & \vdots \\
\mathrm{x}_{11} & \mathrm{x}_{m 2} & \ldots & \mathrm{x}_{m n}
\end{array}\right]
$$

Step 2: Normalize the decision matrix to transform the different attribute dimensions into non-dimensional attributes, which allows comparisons across the values of indicators and participants. The $R$ represents the square root of the additional element value squares, according to each indicator. The $R$ is calculated for each participant $j$ of the decision making matrix.

$$
R_{j}=\sqrt{\sum_{i=1}^{m} x_{i j}^{2}}
$$

for $i=1, \ldots, m ; j=1, \ldots, n$.

Then, divide each column by $R_{j}$ to get $r_{i j}$, which represents the elements of the new normalized decision making matrix and are calculated as:

$$
r_{i j}=x_{i j} / \sqrt{\sum_{i=1}^{m} x_{i j}^{2}}
$$

for $i=1, \ldots, m ; j=1, \ldots, n$.

Step 3: Calculate the weighted normalized decision matrix by multiplying each column of the normalized decision matrix by its linked normalized weight of the impact category, $w_{k}$, for $k=1, \ldots, s$. The importance of every impact category $s$ is not equal due to the different values that are given by the participants; therefore, the assigned impact category' values are aggregated and the average values are normalized, such as: $\sum_{k=1}^{S} w_{j}=1$. The weighted normalized value $\mathrm{v}_{i j}$ is calculated as:

$v_{i j}=w_{k} \times r_{i j}$

Step 4: Specify the most relevant indicator (PIS) and the least relevant indicator (NIS). 
PIS:

$$
\begin{aligned}
& A^{+}=\left\{\left(\max _{i} v_{i j} \mid j \in J_{1}\right),\left(\min _{i j} \mid j \in J_{2}\right) \mid i=1,2, \ldots, m\right\}= \\
& =\left\{v_{1}^{+}, v_{2}^{+}, \ldots, v_{j}^{+}, \ldots, v_{n}^{+}\right\}
\end{aligned}
$$

NIS:

$$
\begin{aligned}
& A^{-}=\left\{\left(\min _{i} v_{i j} \mid j \in J_{1}\right),\left(\max v_{i j} \mid j \in J_{2}\right) \mid i=1,2, \ldots, m\right\}= \\
& =\left\{v_{1}^{-}, v_{2}^{-}, \ldots, v_{j}^{-}, \ldots, v_{n}^{-}\right\}
\end{aligned}
$$

Whereas $J_{1} \subset\{1,2, \ldots, n \mid j-\max \}$ for the max type indicator and $J_{2} \subset\{1,2, \ldots, n \mid j-\min \}$ for the min type indicator.

Step 5: Calculate the Euclidean distances of each indicator $A_{i}$ from the PIS $\left(A^{+}\right)$and of each alternative $A_{i}$ from the NIS $\left(A^{-}\right)$:

$$
\begin{aligned}
& S_{i}^{+}=\sqrt{\sum_{j=1}^{n}\left(v_{i j}-v_{j}^{+}\right)^{2}} \text { and } S_{i}^{-}=\sqrt{\sum_{j=1}^{n}\left(v_{i j}-v_{j}^{-}\right)^{2}} \\
& i=1, \ldots, m
\end{aligned}
$$

Step 6: Calculate the relative closeness of the indicators from the PIS and NIS points. If $C_{i}$ is equal to 1 , then $A_{i}$ is the PIS ( $\left.A^{+}\right)$and if $C_{i}$ is equal to 0 , then $A_{i}$ is the NIS (A).

$$
C_{i}=\frac{S_{i}^{-}}{S_{i}^{+}{ }^{+} S_{i}^{-}} ; 0 \leq C_{i} \leq 1 ; i=1, \ldots, n
$$

Step 7: Rank indicators according to $C_{i}$ and select the indicator with maximum $C_{i}$ as the most relevant indicator.

Table 4 presents an example of the modified TOPSIS procedure based on the results for the consumer group. In Table 4a, 16 decision makers in the consumer group evaluated 11 indicators on a $0-4$ scale. Table $4 \mathrm{~b}$ presents the "Normalized decision matrix R" as described in Step 2 of the method's procedure. The first column contains the impact categories' weights, $w=[0.210,0.149,0.063,0.273,0.302]$. Table $4 \mathrm{c}$ includes the weighted normalized decision matrix, as described in Step 3. The values of each row of the "Normalized decision matrix R" are multiplied with the corresponding criterion weight. Particularly, in the consumers group, the first three alternatives are correlated to criterion 1 (see Table 2); for this reason, the $r_{1 j}, r_{2 j}$ and $r_{3 j}$ values are multiplied with the weight that correlated to criterion $1, w_{1}=0.212$. Finally, Table $4 \mathrm{~d}$ contains the Euclidean distances of each alternative $A_{i}$ to the ideal point $A^{+}$ and of each alternative $A_{i}$ to the negative ideal point $A^{-}$(Step 5), the relative closeness of the alternatives from ideal and non-ideal points $C_{i}$ (Step 6) and the ranking of the alternatives (Step 7) according to the $C_{i}$ value.

\footnotetext{
[Insert Table 4]
} 


\subsubsection{TOPSIS and MEAN: A comparison}

The results of the modified TOPSIS were compared with the average value of the impact categories and indicators defined by MEAN. Later, a Kendall's tau-b $\left(\tau_{\mathrm{b}}\right)$ correlation, as well as the Spearman's rho, were also run using the SPSS software to determine the relationships between the modified TOPSIS and MEAN. Both Spearman's rho and Kendall's tau-b correlation coefficients are nonparametric measures of the strength and direction of association among two observed variables measured on at least an ordinal scale.

\section{Results}

Based on the results of the modified TOPSIS in Table 7, for the consumer group, indicators related to "End of Life Responsibility" and "Transparency" achieved the highest ranks for assessing social impacts of CCU companies, whereas "Fair salary", "Health and Safety" issues, and "Equal Opportunities/Discrimination" received the highest ranks for the workers. Similar to workers, "Safe and Healthy Living Conditions" for the local community received the highest rank, followed by "Secure Living Conditions" and "Local employment' indicators (Table 5).

[Insert Table 5]

As Table 6 shows, based on the experts' view, workers are the group affected the most by CCU activities of a company operating CCU activities, followed by consumers and then local community.

\section{[Insert Table 6]}

\subsection{Comparison of the final ranking: Modified TOPSIS and MEAN}

For making a comparison, the impact categories' weights were determined using the MEAN and modified TOPSIS implemented to rank the indicators (Table 7). It is observed in the final ranking that the normalized values for the first places are higher in the modified TOPSIS, compared to the MEAN method, and lower for the last positions. This indicates that using the modified method provides clear differences in the values of the final rankings as the ranking of the most relevant indicators is influenced more than the lower ranked indicators.

As Table 8 shows, the modified TOPSIS could also overcome the problem with ties. Several tied ranks were observed in all three groups when using the MEAN value, which was not an issue in the results from the modified TOPSIS.

[Insert Table 7]

[Insert Table 8]

A Kendall's tau-b correlation was also run using the SPSS software to determine the relationships between the modified TOPSIS and MEAN amongst 16 participants for the consumers, eight participants for the workers, and nine participants for the local Community groups. As expected based on the resulting rankings, the results are reliable as it is observed that there is a strong positive correlation between the observed variables. Specifically, all correlations were higher than 0.8 and were statistically significant $(\tau b>.800, p<.001)$.

\section{Discussion and conclusion}

Using a five scale survey questionnaire, this study presented a priority list of social impact categories and indicators based on the experts' view for assessing the social impacts of a company operating CCU activities within a European context. By highlighting the priority areas in social considerations, the goal of our study was to support research and development stage of technological innovation, with CCU technologies as a specific example. 
Similar to our survey study, many previous studies have conducted a questionnaire survey among the affected stakeholders to identify the social impact (e.g., Manik et al. 2013). However, the previous studies usually considered only one group of affected stakeholders along the life cycle, while our study took three stakeholders group into consideration. For example, Wang et al. (2016) developed a new methodology according to the UNEP-SETAC guidelines for SLCA and the indicators identified for only one stakeholder category (workers) in the Taiwanese electronics sector. Their results showed that the indicators of child labour, forced labour, fair salary, and equal opportunities/discriminations are the most relevant categories for evaluating the social impacts of Taiwanese electronics companies, according to the evaluation of the 10 experts. By contrast, our results imply that the indicators of "fair salary" and "health and safety" are the most important subcategories followed by the "equal opportunities/discriminations" considerations for assessing the social impacts of a European CCU company with regard to the workers. Previous studies have mainly referred to the generic indicator of "health and safety" without details (e.g., Tyagi et al. 2015), while others have used indicators that can be quantitatively measured, such as the number/percentage of occupational injuries, diseases, and fatalities (e.g., Papong et al. 2015; Colodel et al. 2009). In our study, the injury rate and frequency were identified as the second and third most relevant indicators, while "Lifestyle of Health and Sustainability" (LOHAS) workplace was identified as the most relevant indicator for the assessment of company-worker relationships.

Kuhnen and Hahn (2017) confirmed that researchers overlook major social impacts since they mostly focused on worker- and health-related indicators and excluded the rest due to different reasons and obstacles such as data availability and methodological difficulties. From an industrial perspective, the "consumer" group of stakeholders received moderate attention in the literature, with more concentration on "safe and healthy living conditions"; the latter was also identified in our survey study as the most relevant impact categories for evaluation of the social impacts of a CCU company on consumer. Kuhnen and Hahn (2017) also found that approximately one-third of their sample were concentrated on the consumer indicators, which was identified as the least preferred and often neglected stakeholder group in existing research. In extant studies, scholars have prioritized health and safety indicators (e.g., Maroun and La Rovere 2014; Marshall et al. 2015) as the first rank, whereas in our study these indicators only ranked third, behind the indicators related to "end of life responsibility" and "transparency impact categories". This difference can be associated with the case study and the technology under consideration, as well as the goal of the research survey. In terms of assessing relationships with local community and social impact of industrial companies, the most frequently addressed SLCA category is safe and healthy living conditions, which is also ranked as the most relevant impact category in our study. Given the importance of local community's health conditions, a qualitative description of potential accident risks at local level was considered by Cartelle Barros et al. (2015) and Santoyo-Castelazo and Azapagic (2014), while local morbidity and human health depreciation can be found in the empirical studies of Baumann et al. (2013) and Stamford and Azapagic (2011). In our study, "management effort to minimize use of hazardous substances" and "management oversight of structural integrity" were identified as the most important indicators for assessing CCU companies' performance with regard to the safe and healthy living conditions of the local community.

To ensure that more socially responsible decisions are made, decision makers need tools that facilitate a more comprehensive awareness of potential impacts. The social impact of a product can be determined by social indicators, which are able to assess both negative and positive social impacts. Accordingly, we identified the priority areas of social impacts that need to be taken into consideration by companies at the low TRLs when making decisions about the internal and/or external communication of their social impacts. Identifying the relevant level 
of social impacts seems to be required for detailed actions and further steps towards communication and participation in linking and improving public awareness, with expert knowledge to clearly determine the social impact with regard to CCU, before its application in order to implement more effective strategies to support the deployment of emerging technologies. The detailed results of the most relevant social indicators for CCU can inform technology developers about the priority areas for social impacts caused by their production activities so that they are able to improve or prevent the potential impacted areas. Indeed, in order to achieve a higher TRL of CCU aiming at decreasing operating costs while being socially sustainable, R\&D investments at lower TRL are needed. This would increase awareness at the decision making levels in order to stimulate preventive actions and decrease costs. Based on our findings, the 'health and safety' conditions were identified as one of the most relevant concerns in all the three stakeholder groups. Becoming aware of the potential health and safety impacts at the lower TRL will motivate accident prevention which might result in decreasing accident costs during technology operation. In the consumer stakeholder group, the impact category of 'transparency' refers to information about the product consumers are buying and the social responsibility of the company. With the clear information about the product from the company, consumers can make informed decisions in choosing a product with positive social impacts. Without providing such awareness, the consumer might not have the proper knowledge on the recycling options for the product which may result in environmental problems as well as further economic costs. Another example is the consideration of the impact category 'equal opportunities' in the decision making processes for developing innovative technologies through encouraging, e.g., companies to make their connection stronger with suppliers belonging to minority groups such as businesses with female proprietors. Therefore, taking into account such concerns at lower TRL, where the policy decisions are made for development of such innovative technologies, will not only increase social sustainability performance of a company but also result in its lower economic and environmental costs. Being aware of such social concerns in policy making processes would contribute to the enhancement of resource allocations including time and funding in the development of promising $\mathrm{CCU}$ technologies.

Furthermore, considering the three key steps (design, implementation, and evaluation) in the development of performance measurement approaches (Searcy 2012), including SLCA, our study dealt with the design phase of SLCA for identification of the main social aspects to be considered and identifying relative indicators. Future studies might consider our results as the basis for the implementation and use phase of SLCA within the CCU sector, which is related to the next SLCA steps for collecting and analysing data to provide empirical insights into how indicators are integrated into CCU business decision making processes. Besides, based on the identified social impact categories and indicators in this study, the social sustainability status of different CCU technologies can be compared and, consequently, the most suitable CCU alternative can be determined from the social perspective. 


\section{Reference}

- Afsordegan, A., Sánchez, M., Agell, N., Zahedi, S., \& Cremades, L. V. (2016). Decision making under uncertainty using a qualitative TOPSIS method for selecting sustainable energy alternatives. Int. J. Environ. Sci. Technol.,13, 1419-1432.

- Amine, M.E., Pailhes, J., \& Perry, N. (2014) Comparison of different Multiple-criteria decision analysis methods in the context of conceptual design: application to the development of a solar collector structure. Proceedings of Joint Conference on Mechanical, Design Engineering Advanced Manufacturing, Toulouse, France,, June 2014, France. pp.1-6, 2014.

- Aparcana, S., \& Salhofer, S. (2013). Development of a social impact assess- ment methodology for recycling systems in low-income countries. Int J Life Cycle Assess, 18(5),1106-1115.

- Arning, K., van Heek, J., \& Ziefle, M. (2017). Risk perception and acceptance of CDU consumer products in Germany. Energy Proc. 114, 7186-7196.

- Behzadian, M., Khanmohammadi Otaghsara, S., Yazdani, M., \& Ignatius, J. (2012). A state-of the-art survey of TOPSIS applications. Expert Systems with Applications 39; 13051-13069.

- Bocin-Dumitriu, A., Perez Fortes, M-M., Tzinas, E., \& Sveen, T. Carbon Capture and Utilisation Workshop Background and proceedings. Scientific and Technical Report by the Joint Research Centre of the European Commission. doi:10.2790/11560.

- Bruhn, T., Naims, H., \& Olfe-Kräutlein, B. (2016). Separating the debate on $\mathrm{CO}_{2}$ utilisation from carbon capture and storage. Environmental Science \& Policy, 60, 3843.

- Buchholz, T., Volk, T. A., \& Luzadis, V. A. (2009). Multi criteria analysis for bioenergy systems assessments. Energy Policy, 37(2), 484-495.

- Colodel, C.M., Kupfer, T., Barthel, L. P., \& Albrecht, S. (2009). R\&D decision support by parallel assessment of economic, ecological and social impact: Adipic acid from renewable resources versus adipic acid from crude oil. Ecological Economics, 68(6), 1599-1604.

- Converse, J. M., \& Presser, S. (1986). Survey Questions: Handcrafting the Standardized Questionnaire. Beverly Hills, CA: Sage.

- Cook, C., Heath, F., \& Thompson, R. L. (2000). A meta-analysis of response rates in web- or internet-based surveys. Educational and Psychological Measurement, 60(6), 821-836.

- Cuéllar-Franca, R. M., \& Azapagic, A. (2015). Carbon capture, storage and utilisation technologies: A critical analysis and comparison of their life cycle environmental impacts. Journal of CO2 Utilization, 9,82-102.

- Dikopoulou, Z., Nápoles, G., Papageorgiou, E. I., \& Vanhoof, K. (2015). Ranking and Aggregation of factors affecting companies' attractiveness, 5th International Symposium on Knowledge Acquisition and Modelling, Atlantis Press, London.

- Doukas, H., Karakosta, C., \& Psarras, J. (2010). Computing with words to assess the sustainability of renewable energy options. Expert Syst. Appl., 37, 5491-5497.

- Dreyer, L. C., Hauschild, M. Z., \& Schierbeck, J. (2010). Characterization of social impacts in LCA. Part 1: development of indicators for labour rights. Int $J$ Life Cycle Assess, 15(3), 247-259.

- $\quad$ Ekener-Petersen, E., \& Finnveden, G. (2013). Potential hotspots identified by social LCA_part 1: a case study of a laptop computer. Int J Life Cycle Assess., 18(8),127143.

- EU (2017). Carbon Capture and Utilization. Smart Specialisation Platform, 29/03/2017. http://s3platform.jrc.ec.europa.eu/carbon-capture-and-utilization 
- Foolmaun RK, Ramjeeawon T (2013) Comparative life cycle assessment and social life cycle assessment of used polyethylene terephthalate (PET) bottles in Mauritius. Int $J$ Life Cycle Assess., 18(1), 155-171.

- Gnansounou, E. (2011). Assessing the sustainability of biofuels: a logic-based model. Energy 36(4), 2089e96.

- Harms, D., Hansen, E. G., \& Schaltegger, S. (2013). Strategies in sus- tainable supply chain management: An empirical investigation of large German companies. Corporate Social Responsibility and Environmental Management, 20(4), 205-218.

- Hasan, K. N., Saha, T. K., \& Eghbal, M. (2014). Investigating the priority of market participants for low emission generation entry into the Australian grid. Energy 71, 445455.

- Hassini, E., Surti, C., \& Searcy, C. (2012). A literature review and a case study of sustainable supply chains with a focus on metrics. International Journal of Production Economics, 140(1), 69-82.

- Hossain, M. U., Poon, C. S., Dong, H. Y., Lom, I. M. C., \& Cheng, J. C. P. (2017). Development of social sustainability assessment method and a comparative case study on assessing recycled construction materials. Int $J$ Life Cycle Assess. DOI 10.1007/s11367-017-1373-0.

- Hsieh, L. F., Chin, J. B., Wu, M. C. (2006). Performance evaluation for university electronic libraries in Taiwan. Electron Lib, 24(2), 212-24.

- Huang, I. B., Keisler, J., \& Linkov, I. (2011). Multi-criteria decision analysis in environmental sciences: ten years of applications and trends. Sci Total Environ., 409(19), 3578e94.

- Huguenin, J-M. (2015). Data Envelopment Analysis and non-discretionary inputs: How to select the most suitable model using multi-criteria decision analysis. Expert Systems with Applications, 42, 2570-2581.

- Hwang, A., \& Yoon, K. (1981). Multiple attribute decision making: Methods and applications. New York: Springer-Verlag.

- Jahoda, M., Deutsch, M., \& Cook, S. (1962). Research Methods in Social Relations. New York: Holt, Rinehart and Winston.

- Jamieson, D. (1996). Ethics and intentional climate change. Clim. Change, 33, 323336.

- Jones, C. R, Kaklamanou, D., Stuttard, W. M., Radford, R. L., \& Burley, J. (2015). Investigating public perceptions of carbon dioxide utilisation (CDU) technology: a mixed methods study. Faraday Discuss 183:327-347. DOI: 10.1039/C5FD00063G.

- Jones, C. R., Olfe-Kräutlein, B., Naims, H., \& Armstrong, K. (2017). The Social Acceptance of Carbon Dioxide Utilisation: A Review and Research Agenda. Front. Energy Res. https://doi.org/10.3389/fenrg.2017.00011.

- Jones, S., Snowden-Swan, L., Meyer, P., Zacher, A., Olarte, M., \& Drennan, C. (2015). Fast Pyrolysis and Hydrotreating: 2014 State of Technology R\&D and Projections to 2017. PNNL-24176, Pacific Northwest National Laboratory, Richland WA.

- Kaya, T., \& Kahraman, C. (2011). Multicriteria decision making in energy planning using a modified fuzzy TOPSIS methodology. Expert Systems with Applications, 38, 6577-6585.

- Klankermayer, J., Leitner, W. (2015). Love at second sight for $\mathrm{CO} 2$ and $\mathrm{H} 2$ in organic synthesis. Science, 350, 629-630.

- Kowalewski, S., Arning, K., Minwegen, A., Ziefle, M., \& Ascheid, G. (2012). Extending the engineering trade-off analysis by integrating user preferences in conjoint analysis. Expert Systems with Applications. Retrieved from. doi: http://dx.doi.org/10.1111/risa. 12119. 
- Krosnick, J. A., Holbrook, A. L., et al. (2002). The impact of 'no opinion' response options on data quality. Non-attitude reduction or an invitation to satisfice?. Public Opinion Quarterly, 66, 371-403.

- Kuhnen M, \& Hahn, R. (2017). Indicators in Social Life Cycle Assessment, A Review of Frameworks, Theories, and Empirical Experience. Journal of Industrial Ecology. DOI: $10.1111 /$ jiec.12663.

- Kuramochi, T., Ramírez, A., Turkenburg, W., Faaij, A. (2011). Techno- economic assessment and comparison of $\mathrm{CO}$ capture technologies for industrial processes: preliminary results for the iron and steel sector. Energy Procedia, 4, 1981-1988.

- Manik, Y., Leahy, J., \& Halog, A. (2013). Social life cycle assessment of palm oil biodiesel: a case study in Jambi Province of Indonesia. Int J Life Cycle Assess., 18(7), 1386-1392.

- Mankins, J. C. (2009). Technology readiness assessments: a retrospective. Acta Astronaut, 65,1216-23.

- Martínez-Blanco, J., Lehmann, A., Muñoz, P., Antón, A., Traverso, M., Rieradevall, J., \& Finkbeiner, M. (2014). Application challenges for the social LCA of fertilizers within life cycle sustainability assessment. J Clean Prod., 69, 34-48.

- Maroun, M. R., \& La Rovere, E. L. (2014). Ethanol and food production by family smallholdings in rural Brazil: Economic and socio-environmental analysis of micro distilleries in the State of Rio Grande do Sul. Biomass and Bioenergy, 63, 140-155.

- Marshall, D., McCarthy, L., Heavey, C., \& McGrath, P. (2015). Environmental and social supply chain management sustainability practices: Construct development and measurement. Production Planning \& Control, 26(8), 673-690.

- Marzano, C., Petrov, P., \& Bøwadt, S. (2015). Transforming $\mathrm{CO}_{2}$ into value for a rejuvenated European economy. Proceedings of the scoping workshop European Commission, Brussels, 26 March 2015.

- Mendoza, G. A., \& Prabhu, R. (2003). Qualitative multi-criteria approaches to assessing indicators of sustainable forest resource management. Ecol Manage, 174(13), 329-343.

- Monroe, M. C., \& Adams, D. C. (2012). Increasing response rates to web-based surveys. Journal of Extension 50(6). https://www.joe.org/joe/2012december/tt7.php

- Naims H (2015) Economics of carbon dioxide capture and utilization - a supply and demand perspective. Environ Sci Pollut Res., 23, 22226-22241.

- Niero, M., \& Kalbar, P. (2019). Coupling material circularity indicators and life cycle based indicators: A proposal to advance the assessment of circular economy strategies at the product level. Resources, Conservation and Recycling, 140, 305-312.

- Okoli, C. \& Pawlowski, S.D. (2004). The Delphi method as a research tool: an example, design considerations and applications. Information \& Management, 42(1), 15-29.

- Onat, N. C., Kucukvar, M., Tatari, O., \& Zheng, Q. P. (2016a). Combined application of multi-criteria optimization and life-cycle sustainability assessment for optimal distribution of alternative passenger cars in US. J. Cleaner Prod., 112, 291-307.

- Onat, N. C., Gumus, S., Kucukvar, M., \& Tatari, O. (2016b). Application of the TOPSIS and intuitionistic fuzzy set approaches for ranking the life cycle sustainability performance of alternative vehicle technologies. Sustainable Production and Consumption, 6, 12-25.

- Papong, S., Itsubo, N., Malakul, P., \& Shukuya, M. (2015). Development of the social inventory database in Thailand using input-output analysis. Sustainability, 7(6), 7684 7713.

- Payne, S. (1951). The Art of Asking Questions. Princeton: Princeton University Press. 
- Perdan S, Jones CR, Azapagic A (2017) Public awareness and acceptance of carbon capture and utilisation in the UK. Sustainable Prod. Consumption., 10, 74-84. doi:10.1016/j.spc.2017.01.001.

- Pérez-Fortes, M., \& Tzimas, E. (2016). Techno-economic and environmental evaluation of carbon dioxide utilisation for fuel production. Synthesis of methanol and formic acid; EUR $27629 \mathrm{EN}$; doi: 10.2790/981669.

- Pieri, T., Nikitas, A., Castillo-Castillo A., and Angelis-Dimakis, A. (2018). Holistic Assessment of Carbon Capture and Utilization Value Chains. Environments, 5, 108. doi:10.3390/environments5100108.

- Poe, G. S., Seeman, I., McLaughlin, J., Mehl, E., \& Dietz, M. (1988). Don't know boxes in factual questions in a mail questionnaire. Public Opinion Quarterly 52, 212- 222.

- Quadrelli, E., Centi, G., Duplan, J-L., Perathoner, S. (2011). Carbon dioxide recycling: emerging large-scale technologies with industrial potential, ChemSusChem, 4, 1941215.

- Rafiaani, P., Kuppens, T., Van Dael, M., Azadi, H., Lebailly, Ph., \& Van Passel, S. (2018). Social sustainability assessments in the biobased economy: Towards a systemic approach. Journal of Renewable and Sustainable Energy Reviews, 82(2), 1839-1853.

- Ragland, C. J., Feldpausch-Parker, A., Peterson, T. R, Stephens, J., \& Wilson, E. (2011). Socio-political dimensions of CCS deployment through the lens of social network analysis. Energy Procedia, 4, 6210-6217.

- Rogers, E. (2003). Diffusion of Innovations. Free Press, New York, NY.

- Rubin, E.S., Mantripragad, H., Marks, A., Versteeg, P \& Kitchin, J. (2012). The outlook for improved carbon capture technology. Progress in Energy and Combustion Science xxx (2012) 1-42. doi:10.1016/j.pecs.2012.03.003.

- Scott, JA., Ho, W., \& Dey, P. K. (2012). A review of multi-criteria decision- making methods for bioenergy system. Energy, 42(1),146-156.

- Streimikiene, D., Balezentis, T., Krisciukaitiene, I., \& Balezentis, A. (2012). Prioritizing sustainable electricity production technologies: MCDM approach. Renewable Sustainable Energy Rev., 16, 3302-3311.

- Sultana, A., \& Kumar, A. (2012). Ranking of biomass pellets by integration of economic, environmental and technical factors. Biomass Bioenergy, 2(39), 344-355.

- Thomassen, G., Van Dael, M., and Van Passel, S. 2018. The potential of microalgae biorefineries in Belgium and India: An environmental techno-economic assessment. Bioresour Technol., 267:271-280.

- Traverso, M., Asdrubali, F., Francia. A., \& Finkbeiner, M. (2012). Towards life cycle sustainability assessment: an implementa- tion to photovoltaic modules. Int J Life Cycle Assess., 17(8), 1068-1079.

- Turcksin, L., Macharis, C., Lebeau, K., Boureima, F., Mierlo, J. V., Bram, S., et al. (2011). A multi-actor multi-criteria framework to assess the stakeholder support for different biofuel options: the case of Belgium. Energy Policy, 39(1), 200-214.

- Tyagi, M., Kumar, P., \& Kumar, D. (2015). Analyzing CSR issues for supply chain performance system using preference rating approach. Journal of Manufacturing Technology Management, 26(6), 830-852.

- UNEP/SETAC (2009). Guidelines for social life cycle assessment of products, UNEP/SETAC Life Cycle Initiative. Benoît $\mathrm{C}$ and Mazijn B. http://www.unep.fr/shared/publications/pdf/DTIx1164xPA-guidelines_sLCA.pdf.

- Vaillancourt, P. M. (1973). Stability of children's survey responses. Public Opinion Quarterly, 37, 373-387.

- $\quad$ van Heek, J., Arning, K., \& Ziefle, M. (2017). Reduce, reuse, recycle: Acceptance of CO-utilization for plastic products. Energy Policy, 105, 53-66. 
- Van Schoubroeck, S., Springael, J., Van Dael, M., Malina, R., \& Van Passel, S. (2019). Sustainability indicators for biobased chemicals: A Delphi study using Multi-Criteria Decision Analysis. Resources, Conservation and Recycling, 144, 198-208.

- Velasquez, M., \& Hester, P. T. (2013). An Analysis of Multi-Criteria Decision Making Methods. International Journal of Operations Research, 10(2), 56-66.

- Vinyes, E., Oliver-Solà, J., Ugaya, C., Rieradevall, J., \& Gasol, C. M. (2013). Application of LCSA to used cooking oil waste management. Int J Life Cycle Assess., 18(2), 445-455.

- Vreys, K., Lizin, S., Van Dael, M., Tharakan, J., \& Malina, R (2019). Exploring the future of carbon capture and utilisation by combining an international Delphi study with local scenario development. Resources, Conservation and Recycling (in press).

- Wang, J-J., Jing, Y-Y., Zhang, C-F., \& Zhao, J-H. (2009). Review on multi-criteria decision analysis aid in sustainable energy decision-making. Renewable and Sustainable Energy Reviews, 13(9), 2263-2278.

- Wang, E. (2015). Benchmarking whole-building energy performance with multicriteria technique for order preference by similarity to ideal solution using a selective objective- weighting approach. Appl. Energy, 146, 92-103.

- Wang, S-W., Hsu, C-W., \& Hu, A. H. (2016). An analytic framework for social life cycle impact assessment - part 1: methodology. Int J Life Cycle Assess 21, 15141528.

- Wassermann, S., Schulz, M., \& Scheer, D. (2011). Linking public acceptance with expert knowledge on COstorage. Outcomes of a Delphi approach. Energy Procedia 4, 6353-6359.

- Wilson, G., Travaly, Y., Brun, T., Knippels, H., Armstrong, K., Styring, P., et al. (2015). A Vision for Smart CO2 Transformation in Europe: Using CO2 as a Resource. SCOT Project. Available at: http://www.scotproject.org/images/SCOT\%20Vision.pdf.

- Xu, Q., Zhang, Y-B., Zhang, J., \& Lv, X-G. (2015). Improved TOPSIS Model and its Application in the Evaluation of NCAA Basketball Coaches Modern Applied Science 9(2). http://www.ccsenet.org/journal/index.php/mas/article/view/41201.

- Zaunbrecher, B. S., \& Ziefle, M. (2016). Integrating acceptance-relevant factors into wind power planning: A discussion. Sustainable Cities and Society. http://dx.doi.org/ 10.1016/j.scs.2016.08.018.

- Zhang, Z. (2016). Missing data imputation: focusing on single imputation. Ann Transl Med., 4(1),9. doi: 10.3978/j.issn.2305-5839.2015.12.38.

- Zimmermann, A. W., \& Schomacker, R. (2017). Assessing Early-Stage $\mathrm{CO}_{2}$ utilization Technologies - Comparing Apples and Oranges? Energy Technol., 5, 850 - 860. DOI: 10.1002/ente.201600805. 
Table 1 Technology readiness level of a set of CCU technologies and $\mathrm{CO}_{2}$ applications (Source: EU, 2017)

\begin{tabular}{|c|c|c|}
\hline CCU category & Technology/application & TRL $^{*}(1-9)$ \\
\hline \multirow{8}{*}{$\mathrm{CO}_{2}$ to fuels } & Renewable methanol and methane production & 4-8 \\
\hline & Formic acid production & 5 \\
\hline & Algae cultivation & $3-5$ \\
\hline & Helioculture & 3 \\
\hline & $\begin{array}{l}\text { Counter rotating ring receiver reactor } \\
\text { recuperator }\end{array}$ & 3 \\
\hline & Photocatalytic reduction of $\mathrm{CO}_{2}$ (metallic) & 3 \\
\hline & Photocatalytic reduction of $\mathrm{CO}_{2}$ (non-metallic) & 3 \\
\hline & Nanomaterial catalysts & $2-3$ \\
\hline \multirow{4}{*}{$\begin{array}{l}\text { Enhanced commodity } \\
\text { production }\end{array}$} & Enhanced Geothermal System with $\mathrm{CO}_{2}$ & 4 \\
\hline & Supercritical $\mathrm{CO}_{2}$ power cycles & 3 \\
\hline & Urea yield boosting & 9 \\
\hline & Methanol yield boosting (conventional) & 9 \\
\hline \multirow[t]{4}{*}{$\mathrm{CO}_{2}$ mineralisation } & Mineral carbonation & $3-7$ \\
\hline & Sodium bicarbonate & 6 \\
\hline & $\mathrm{CO}_{2}$ concrete curing & 5 \\
\hline & Bauxite residue carbonation & 8 \\
\hline \multirow{2}{*}{$\begin{array}{l}\mathrm{CO}_{2} \text { as chemicals } \\
\text { feedstock }\end{array}$} & Polymer processing (polycarbonates) & $3-5$ \\
\hline & Polymer processing (polyurethanes) & $3-5$ \\
\hline \multirow{3}{*}{$\begin{array}{l}\text { Other existing commercial } \\
\text { applications }\end{array}$} & Food and beverage applications & 9 \\
\hline & Horticulture & 9 \\
\hline & Other industrial and technical uses & 9 \\
\hline
\end{tabular}


eholders, impact categories, and indicators for social impacts of Carbon Capture and Utilization (CCU) activities of a itext (UNEP/SETAC, 2009)

\begin{tabular}{|c|c|c|}
\hline \multirow{19}{*}{$\frac{\text { lolder }}{\text { rs }}$} & Impact category & Indicator \\
\hline & \multirow{5}{*}{$\begin{array}{l}\text { Freedom of Association and } \\
\text { Collective Bargaining (A1) }\end{array}$} & Rate of labor dispute involvement (A1a) \\
\hline & & Rate of labor union organization (A1b) \\
\hline & & Rate of dispatching (part-time) workers (A1c) \\
\hline & & Promoting freedom of association (A1d) \\
\hline & & Right to collective bargaining (A1e) \\
\hline & \multirow[t]{2}{*}{ Fair Salary (A2) } & Minimum and fair wages for worker (A2a) \\
\hline & & Social benefits provided to workers (A2b) \\
\hline & \multirow[t]{2}{*}{ Working Hours (A3) } & Per month average working hours (male and females) (A3a) \\
\hline & & Management of overtime hours (A3b) \\
\hline & \multirow{3}{*}{$\begin{array}{l}\text { Equal } \\
\text { Opportunities/Discrimination } \\
\text { (A4) }\end{array}$} & Rate of disability employment (A4a) \\
\hline & & $\begin{array}{l}\text { Protecting worker against discrimination during both the recruitment process and the term c } \\
\text { employment (A4b) }\end{array}$ \\
\hline & & Ratio of basic salary of men to women by employee category (A4c) \\
\hline & \multirow[t]{4}{*}{ Health and Safety (A5) } & Disabling injury frequency rate (A5a) \\
\hline & & Disabling injury severity rate (A5b) \\
\hline & & Proposed penalty case rate (A5c) \\
\hline & & Lifestyle of Health and Sustainability (LOHAS) workplace (A5d) \\
\hline & \multirow{2}{*}{$\begin{array}{l}\text { Social Benefits/Social Security } \\
\text { (A6) }\end{array}$} & Percentage of permanent workers receiving paid time-off (A6a) \\
\hline & & $\begin{array}{l}\text { Evidence of violations of obligations to workers under labour or social security lav } \\
\text { employment regulations (A6b) }\end{array}$ \\
\hline \multirow[t]{11}{*}{ mers } & \multirow[t]{3}{*}{ Health and Safety (B1) } & The number of consumer complaints related to consumer health and safety (B1a) \\
\hline & & Presence of management measures to assess consumer health and safety (B1b) \\
\hline & & Quality of labels of health and safety requirements (B1c) \\
\hline & \multirow[t]{2}{*}{ Feedback Mechanism (B2) } & Presence of a mechanism for customers to provide feedback (B2a) \\
\hline & & Presence of practices related to customer satisfaction (B2b) \\
\hline & \multirow[t]{2}{*}{ Consumer Privacy (B3) } & $\begin{array}{l}\text { The number of complaints by regulatory bodies related to breach of consumer privacy or } \\
\text { data within the last year (B3a) }\end{array}$ \\
\hline & & Strength of internal management system to protect consumer privacy, in general (B3b) \\
\hline & \multirow[t]{2}{*}{ Transparency (B4) } & Certification/label the company obtained for the product/site (B4a) \\
\hline & & Company rating in sustainability indices (B4b) \\
\hline & \multirow[t]{2}{*}{ End of Life Responsibility (B5) } & $\begin{array}{l}\text { Clear information provided by internal management systems to consumers on end-of-life c } \\
\text { (B5a) }\end{array}$ \\
\hline & & Annual incidents of non- compliance with regulatory labelling requirements (B5b) \\
\hline
\end{tabular}




\begin{tabular}{|c|c|c|}
\hline & Access to Material Resources $(\mathrm{C} 1)$ & Strength of company's risk assessment regarding potential for material resource conflict (C \\
\hline & & Having a certified environmental management system $(\mathrm{C} 1 \mathrm{~b})$ \\
\hline & Access to Immaterial Resources & Annual arrests connected to protests of company's actions (C2a) \\
\hline & & Presence/strength of community education initiatives $(\mathrm{C} 2 \mathrm{~b})$ \\
\hline & Safe and Healthy Living & Management oversight of structural integrity (C3a) \\
\hline & Conditions (C3) & Company's efforts to strengthen community health (C3b) \\
\hline & & Management effort to minimize use of hazardous substances (C3c) \\
\hline & & Number and quality of meetings with community stakeholders (C4a) \\
\hline community & & Company's support (volunteer- hours or financial) for community initiatives (C4b) \\
\hline & Community Engagement (C4) & Diversity of community stakeholder groups that engage with the company $(\mathrm{C} 4 \mathrm{c})$ \\
\hline & & Strength of written policies on community engagement at company level (C4d) \\
\hline & & Percentage of workforce hired locally (C5a) \\
\hline & Local Employment (C5) & Percentage of spending on locally- based suppliers (C5b) \\
\hline & & Strength of policies on local hiring preferences (C5c) \\
\hline & Secure I ivina Conditions (C6) & $\begin{array}{l}\text { Number of legal complaints per year against the company with regard to security co } \\
\text { Conditions (C6a) }\end{array}$ \\
\hline & Secure Living Conditions (Co) & Number of casualties and injuries per year ascribed to the company Conditions (C6b) \\
\hline & & Management policies related to private security personnel Conditions (C6c) \\
\hline
\end{tabular}




$\begin{array}{cccc}\text { Male } & 81,3 \% & 50,0 \% & 77,8 \% \\ \text { Female } & 18,8 \% & 50,0 \% & 22,2 \% \\ \text { Age } & & & \\ 25-44 & 18,3 \% & 75,0 \% & 55,6 \% \\ 45-65 & 81,3 \% & 25,0 \% & 44,4 \%\end{array}$

$\begin{array}{cccc}\text { Company activity } & & & - \\ \text { Cement industry } & 6,3 \% & - & - \\ \text { Chemical industry } & 6,3 \% & 25,0 \% & - \\ \text { Consulting } & 12,5 \% & - & 11,1 \% \\ \text { Educational sector } & 18,8 \% & 25,0 \% & 11,1 \% \\ \text { Government } & 12,5 \% & - & 11,1 \% \\ \text { Industry association } & 6,3 \% & - & - \\ \text { Manufacturing industry } & 6,3 \% & - & 33,3 \% \\ \text { Research institute } & 31,3 \% & 50,0 \% & 11,1 \% \\ \text { Oil and gas industry } & - & - & 11,1 \% \\ \text { Finance industry } & - & - & 11,1 \% \\ \text { CCS industry } & - & - & \end{array}$




\begin{tabular}{|c|c|c|c|c|c|c|c|c|c|c|c|}
\hline \multicolumn{5}{|c|}{$\begin{array}{c}\text { a } \\
\text { Decision matrix } D\end{array}$} & \multicolumn{7}{|c|}{$\begin{array}{c}\text { b } \\
\text { Normalized decision matrix } R\end{array}$} \\
\hline \multicolumn{2}{|r|}{$P_{1}$} & \multirow{2}{*}{$\frac{P_{2}}{2}$} & \multirow{2}{*}{$\begin{array}{ll}\cdots \\
\cdots\end{array}$} & \multirow{2}{*}{$\begin{array}{c}P_{16} \\
4\end{array}$} & \multicolumn{2}{|c|}{ weights } & \multicolumn{2}{|r|}{$P_{1}$} & \multirow{2}{*}{$\frac{P_{2}}{0230}$} & \multirow{2}{*}{$\begin{array}{l}\ldots \\
\ldots\end{array}$} & \multirow{2}{*}{$\begin{array}{c}\boldsymbol{P}_{\mathbf{1 6}} \\
0.357\end{array}$} \\
\hline $\mathbf{B 3}_{\mathrm{a}}$ & 3 & & & & & & $\mathbf{B 1}_{\mathbf{a}}$ & 0.272 & & & \\
\hline $\mathbf{B 3}_{\mathrm{b}}$ & 4 & 3 & $\ldots$ & 4 & & & $\mathbf{B} \mathbf{1}_{\mathrm{b}}$ & 0.363 & 0.358 & $\ldots$ & 0.357 \\
\hline $\mathbf{B 3}_{\mathrm{c}}$ & 3 & 3 & $\ldots$ & 3 & & & $\mathbf{B} \mathbf{1}_{\mathrm{c}}$ & 0.272 & 0.358 & $\ldots$ & 0.268 \\
\hline $\mathbf{B} \mathbf{a}_{\mathrm{a}}$ & 3 & 1 & $\ldots$ & 3 & & & $\mathbf{B} \mathbf{a}_{\mathrm{a}}$ & 0.272 & 0.119 & $\ldots$ & 0.268 \\
\hline $\mathbf{B} \mathbf{2}_{\mathrm{b}}$ & 3 & 3 & $\ldots$ & 3 & & & $\mathbf{B} \mathbf{2}_{\mathrm{b}}$ & 0.272 & 0.358 & $\ldots$ & 0.268 \\
\hline $\mathbf{B 3}_{\mathbf{a}}$ & 4 & 2 & $\ldots$ & 1 & & & $\mathbf{B 3}_{\mathrm{a}}$ & 0.363 & 0.239 & $\ldots$ & 0.089 \\
\hline $\mathbf{B 3}_{\mathrm{b}}$ & 4 & 2 & & 1 & & & $\mathbf{B 3}_{\mathrm{b}}$ & 0.363 & 0.239 & & 0.089 \\
\hline $\mathbf{B 4} \mathbf{a}_{\mathbf{a}}$ & 4 & 2 & & 4 & & & $\mathbf{B 4}_{\mathrm{a}}$ & 0.363 & 0.239 & & 0.357 \\
\hline $\mathbf{B 4}_{b}$ & 1 & 1 & & 4 & & & B4 $4_{b}$ & 0.090 & 0.119 & & 0.357 \\
\hline $\mathbf{B 5}_{\mathbf{a}}$ & 4 & 4 & & 4 & & & $\mathbf{B 5}_{\mathrm{a}}$ & 0.363 & 0.478 & & 0.357 \\
\hline $\mathbf{B 5}_{\mathrm{b}}$ & 2 & 3 & & 4 & & & $\mathbf{B 5}_{\mathrm{b}}$ & 0.181 & 0.358 & & 0.357 \\
\hline \multicolumn{5}{|c|}{ c } & \multicolumn{7}{|c|}{ d } \\
\hline \multicolumn{5}{|c|}{ Weighted normalized decision matrix $V$} & \multicolumn{7}{|c|}{ Ranking } \\
\hline & $P_{1}$ & $P_{2}$ & $\ldots$ & $P_{16}$ & \multicolumn{3}{|c|}{$S_{i}^{+}$} & \multicolumn{2}{|l|}{$S_{i}^{-}$} & $C_{i}$ & Rank \\
\hline $\mathbf{B 1}_{a}$ & 0.057 & 0.050 & $\ldots$ & 0.075 & B1 $_{a}$ & \multicolumn{2}{|c|}{0.378} & \multicolumn{2}{|l|}{0.157} & 0.293 & 7 \\
\hline $\mathbf{B 1}_{b}$ & 0.076 & 0.075 & $\ldots$ & 0.075 & $\mathbf{B} \mathbf{1}_{\mathrm{b}}$ & \multicolumn{2}{|c|}{0.340} & 0.200 & & 0.370 & 6 \\
\hline $\mathbf{B 1}_{c}$ & 0.057 & 0.075 & $\ldots$ & 0.056 & B1 $1_{c}$ & \multirow{2}{*}{\multicolumn{2}{|c|}{$\begin{array}{l}0.305 \\
0.345\end{array}$}} & 0.188 & & 0.381 & 5 \\
\hline $\mathrm{B} 2_{a}$ & 0.040 & 0.017 & $\ldots$ & 0.040 & $\mathbf{B} \mathbf{2}_{\mathrm{a}}$ & & & 0.135 & & 0.282 & 8 \\
\hline $\mathbf{B} \mathbf{2}_{\mathrm{b}}$ & 0.040 & 0.053 & $\ldots$ & 0.040 & $\mathbf{B} \mathbf{2}_{\mathrm{b}}$ & \multicolumn{2}{|c|}{0.346} & 0.128 & & 0.270 & 9 \\
\hline $\mathbf{B 3}_{\mathrm{a}}$ & 0.023 & 0.015 & $\ldots$ & 0.005 & $\mathbf{B 3}_{\mathrm{a}}$ & \multicolumn{2}{|c|}{0.458} & 0.021 & & 0.044 & 10 \\
\hline $\mathbf{B 3}_{\mathrm{b}}$ & 0.023 & 0.015 & & 0.005 & $\mathbf{B 3}_{\mathrm{b}}$ & & 0.020 & & 0.042 & 11 \\
\hline $\mathbf{B} 4_{a}$ & 0.099 & 0.063 & & 0.097 & B4 $\mathbf{a}_{\mathrm{a}}$ & \multicolumn{2}{|c|}{0.158} & 0.359 & & 0.693 & 2 \\
\hline $\mathbf{B} \mathbf{4}_{\mathrm{b}}$ & 0.024 & 0.032 & & 0.097 & $\mathbf{B 4}_{b}$ & \multicolumn{2}{|c|}{0.225} & 0.304 & & 0.574 & 4 \\
\hline $\mathbf{B 5}_{\mathbf{a}}$ & 0.110 & 0.144 & & 0.108 & $\mathbf{B 5}_{\mathrm{a}}$ & \multirow{2}{*}{\multicolumn{2}{|c|}{0.045}} & 0.452 & & 0.908 & 1 \\
\hline $\mathbf{B 5}_{\mathrm{b}}$ & 0.055 & 0.108 & & 0.108 & $\mathbf{B 5}_{\mathrm{b}}$ & & & 0.343 & & 0.583 & 3 \\
\hline
\end{tabular}


lts of the Modified TOPSIS for the weights of the sub-categories and rankings of the indicators

\begin{tabular}{|c|c|c|c|c|}
\hline$\overline{\mathrm{der}}$ & Subcategory & $\begin{array}{c}\text { Weight of } \\
\text { subcategory }\end{array}$ & Indicator & $\mathrm{CCi}$ \\
\hline \multirow{18}{*}{ rs } & \multirow{5}{*}{$\begin{array}{l}\text { Freedom of Association and Collective } \\
\text { Bargaining (A1) }\end{array}$} & \multirow[t]{5}{*}{0.045} & Rate of labor dispute involvement (A1a) & 0,070 \\
\hline & & & Rate of labor union organization (A1b) & 0,072 \\
\hline & & & Rate of dispatching (part-time) workers (A1c) & 0,078 \\
\hline & & & Promoting freedom of association (A1d) & 0,093 \\
\hline & & & Right to collective bargaining (A1e) & 0,089 \\
\hline & \multirow[t]{2}{*}{ Fair Salary (A2) } & \multirow[t]{2}{*}{0.231} & Minimum and fair wages for worker (A2a) & 0,875 \\
\hline & & & Social benefits provided to workers (A2b) & 0,734 \\
\hline & \multirow[t]{2}{*}{ Working Hours (A3) } & \multirow[t]{2}{*}{0.172} & Per month average working hours (male and females) (A3a) & 0,678 \\
\hline & & & Management of overtime hours (A3b) & 0,567 \\
\hline & \multirow[t]{3}{*}{ Equal Opportunities/Discrimination (A4) } & \multirow[t]{3}{*}{0.186} & Rate of disability employment (A4a) & 0,441 \\
\hline & & & $\begin{array}{l}\text { Protecting worker against discrimination during both the recruitment process and } \\
\text { the term of your employment }(\mathrm{A} 4 \mathrm{~b})\end{array}$ & 0,605 \\
\hline & & & Ratio of basic salary of men to women by employee category (A4c) & 0,659 \\
\hline & \multirow[t]{4}{*}{ Health and Safety (A5) } & \multirow[t]{4}{*}{0.214} & Disabling injury frequency rate (A5a) & 0,845 \\
\hline & & & Disabling injury severity rate (A5b) & 0,929 \\
\hline & & & Proposed penalty case rate $(\mathrm{A} 5 \mathrm{c})$ & 0,522 \\
\hline & & & Lifestyle of Health and Sustainability (LOHAS) workplace (A5d) & 0,724 \\
\hline & \multirow[t]{2}{*}{ Social Benefits/Social Security (A6) } & \multirow[t]{2}{*}{0.149} & Percentage of permanent workers receiving paid time-off (A6a) & 0,379 \\
\hline & & & $\begin{array}{l}\text { Evidence of violations of obligations to workers under labour or social security } \\
\text { laws and employment regulations (A6b) }\end{array}$ & 0,394 \\
\hline \multirow{11}{*}{ ers } & \multirow[t]{3}{*}{ Health and Safety (B1) } & \multirow[t]{3}{*}{0.210} & The number of consumer complaints related to consumer health and safety (B1a) & 0,293 \\
\hline & & & Presence of management measures to assess consumer health and safety (B1b) & 0,370 \\
\hline & & & Quality of labels of health and safety requirements (B1c) & 0,381 \\
\hline & \multirow[t]{2}{*}{ Feedback Mechanism (B2) } & \multirow[t]{2}{*}{0.149} & Presence of a mechanism for customers to provide feedback (B2a) & 0,282 \\
\hline & & & Presence of practices related to customer satisfaction (B2b) & 0,270 \\
\hline & \multirow[t]{2}{*}{ Consumer Privacy (B3) } & \multirow[t]{2}{*}{0.063} & $\begin{array}{l}\text { The number of complaints by regulatory bodies related to breach of consumer } \\
\text { privacy or loss of data within the last year (B3a) }\end{array}$ & 0,044 \\
\hline & & & $\begin{array}{l}\text { Strength of internal management system to protect consumer privacy, in general } \\
\text { (B3b) }\end{array}$ & 0,042 \\
\hline & \multirow[t]{2}{*}{ Transparency (B4) } & \multirow[t]{2}{*}{0.273} & Certification/label the company obtained for the product/site (B4a) & 0,693 \\
\hline & & & Company rating in sustainability indices (B4b) & 0,574 \\
\hline & \multirow[t]{2}{*}{ End of Life Responsibility (B5) } & \multirow[t]{2}{*}{0.302} & $\begin{array}{l}\text { Clear information provided by internal management systems to consumers on end- } \\
\text { of-life options (B5a) }\end{array}$ & 0,908 \\
\hline & & & Annual incidents of non- compliance with regulatory labelling requirements (B5b) & 0,583 \\
\hline \multirow{5}{*}{ nunity } & \multirow[t]{2}{*}{ Access to Material Resources (C1) } & \multirow[t]{2}{*}{0.085} & $\begin{array}{l}\text { Strength of company's risk assessment regarding potential for material resource } \\
\text { conflict }(\mathrm{C} 1 \mathrm{a})\end{array}$ & 0,177 \\
\hline & & & Having a certified environmental management system $(\mathrm{C} 1 \mathrm{~b})$ & 0,195 \\
\hline & \multirow[t]{2}{*}{ Access to Immaterial Resources (C2) } & \multirow[t]{2}{*}{0.069} & Annual arrests connected to protests of company's actions (C2a) & 0,125 \\
\hline & & & Presence/strength of community education initiatives $(\mathrm{C} 2 \mathrm{~b})$ & 0,157 \\
\hline & Safe and Healthy Living Conditions (C3) & 0.246 & Management oversight of structural integrity (C3a) & 0,660 \\
\hline
\end{tabular}




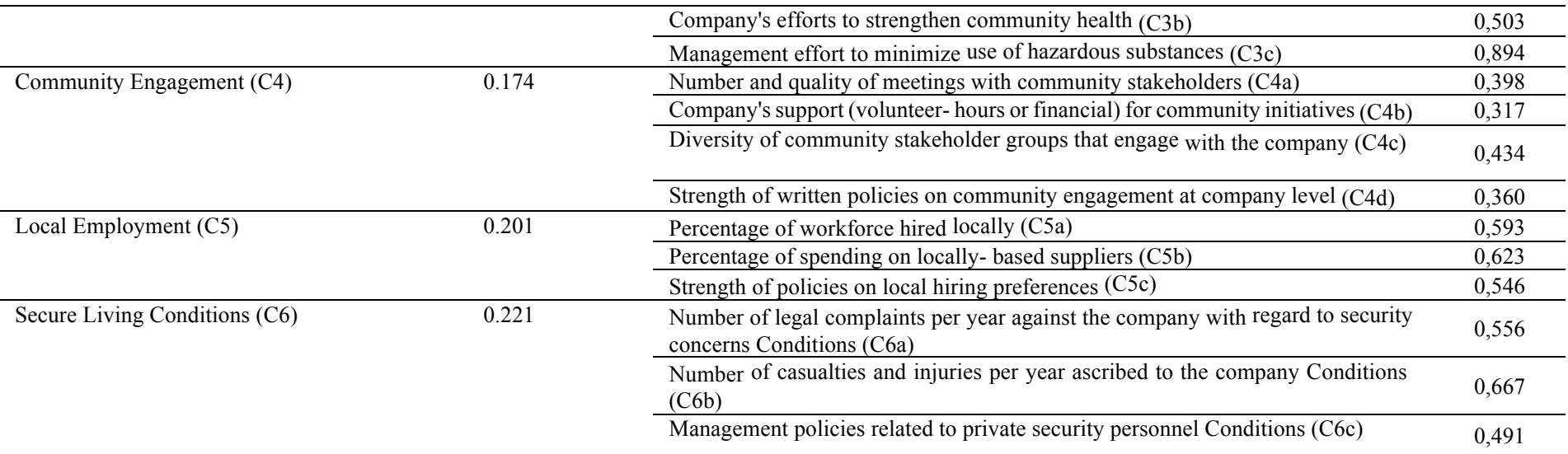




\begin{tabular}{|c|c|c|c|c|c|}
\hline & & $\stackrel{0}{\Xi}$ & 茞 & 苨 & $\stackrel{\text { Iี }}{\simeq}$ \\
\hline \multirow[t]{5}{*}{ Consumers } & End of Life Responsibility & 0,302 & 1 & 0,236 & 1 \\
\hline & Transparency & 0,273 & 2 & 0,214 & 2 \\
\hline & Health and Safety & 0,210 & 3 & 0,214 & 3 \\
\hline & Feedback Mechanism & 0,149 & 4 & 0,179 & 4 \\
\hline & Consumer Privacy & 0,063 & 5 & 0,153 & 5 \\
\hline \multirow[t]{6}{*}{ Workers } & Fair Salary & 0,231 & 1 & 0,192 & 1 \\
\hline & Health and Safety & 0,214 & 2 & 0,186 & 2 \\
\hline & Equal Opportunities/Discrimination & 0,186 & 3 & 0,173 & 3 \\
\hline & Working Hours & 0,172 & 4 & 0,167 & 4 \\
\hline & Social Benefits/Social Security & 0,149 & 5 & 0,155 & 5 \\
\hline & $\begin{array}{l}\text { Freedom of Association and Collective } \\
\text { Bargaining }\end{array}$ & 0,045 & 6 & 0,124 & 6 \\
\hline \multirow{6}{*}{$\begin{array}{l}\text { Local } \\
\text { community }\end{array}$} & Safe and Healthy Living Conditions & 0,246 & 1 & 0,212 & 1 \\
\hline & Secure Living Conditions & 0,221 & 2 & 0,196 & 2 \\
\hline & Local Employment & 0,201 & 3 & 0,173 & 3 \\
\hline & Community Engagement & 0,174 & 4 & 0,165 & 4 \\
\hline & Access to Material Resources & 0,085 & 5 & 0,125 & 5 \\
\hline & Access to Immaterial Resources & 0,069 & 6 & 0,125 & 5 \\
\hline
\end{tabular}




\begin{tabular}{|c|c|c|c|c|c|c|}
\hline & & & 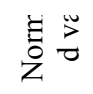 & 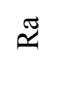 & $\stackrel{n}{z}$ & $\approx$ \\
\hline \multirow[t]{11}{*}{ Consumers } & \multirow[t]{3}{*}{ End of Life Responsibility } & $\mathrm{Al}_{\mathrm{a}}$ & 0,293 & 7 & 0,072 & 11 \\
\hline & & $\mathrm{Al}_{\mathrm{b}}$ & 0,370 & 6 & 0,093 & 4 \\
\hline & & $\mathrm{Al}_{\mathrm{c}}$ & 0,381 & 5 & 0,084 & 8 \\
\hline & \multirow[t]{2}{*}{ Transparency } & $\mathrm{A} 2_{\mathrm{a}}$ & 0,282 & 8 & 0,089 & 5 \\
\hline & & $\mathrm{A} \mathrm{z}_{\mathrm{b}}$ & 0,270 & 9 & 0,086 & 7 \\
\hline & \multirow[t]{2}{*}{ Health and Safety } & $\mathrm{A3}_{\mathrm{a}}$ & 0,044 & 10 & 0,076 & 9 \\
\hline & & $\mathrm{A} 3_{\mathrm{b}}$ & 0,042 & 11 & 0,076 & 9 \\
\hline & \multirow{2}{*}{ Feedback Mechanism } & $\mathrm{A}_{\mathrm{a}}$ & 0,693 & 2 & 0,112 & 2 \\
\hline & & $\mathrm{A} 4_{\mathrm{b}}$ & 0,574 & 4 & 0,089 & 5 \\
\hline & \multirow[t]{2}{*}{ Consumer Privacy } & $\mathrm{A5}_{\mathrm{a}}$ & 0,908 & 1 & 0,119 & 1 \\
\hline & & $\mathrm{A} 5_{\mathrm{b}}$ & 0,583 & 3 & 0,099 & 3 \\
\hline \multirow[t]{18}{*}{ Workers } & \multirow[t]{5}{*}{ Fair Salary } & $\mathrm{B} 1_{\mathrm{a}}$ & 0,070 & 18 & 0,036 & 18 \\
\hline & & $\mathrm{B} 1_{\mathrm{b}}$ & 0,072 & 17 & 0,039 & 16 \\
\hline & & $\mathrm{B} 1_{\mathrm{c}}$ & 0,078 & 16 & 0,039 & 16 \\
\hline & & $B 1_{d}$ & 0,093 & 14 & 0,046 & 14 \\
\hline & & $B 1_{\mathrm{e}}$ & 0,089 & 15 & 0,051 & 10 \\
\hline & \multirow{2}{*}{ Health and Safety } & $\frac{\mathrm{B} 2 \mathrm{a}}{\mathrm{a}}$ & 0,875 & 2 & 0,068 & 4 \\
\hline & & $\mathrm{B} 2_{\mathrm{b}}$ & 0,734 & 4 & 0,061 & 6 \\
\hline & \multirow[t]{2}{*}{ Equal Opportunities/Discrimination } & $\mathrm{B} 3_{\mathrm{a}}$ & 0,678 & 6 & 0,071 & 2 \\
\hline & & $\mathrm{B} 3_{\mathrm{a}}$ & 0,567 & 9 & 0,058 & 9 \\
\hline & \multirow{3}{*}{ Working Hours } & $\mathrm{B} 4_{\mathrm{a}}$ & 0,441 & 11 & 0,046 & 14 \\
\hline & & $\mathrm{B} 4_{\mathrm{b}}$ & 0,605 & 8 & 0,061 & 6 \\
\hline & & $\mathrm{B} 4_{\mathrm{c}}$ & 0,659 & 7 & 0,066 & 5 \\
\hline & \multirow[t]{4}{*}{ Social Benefits/Social Security } & $B 5_{a}$ & 0,845 & 3 & 0,071 & 2 \\
\hline & & $B 5_{b}$ & 0,929 & 1 & 0,073 & 1 \\
\hline & & $B 5_{c}$ & 0,522 & 10 & 0,049 & 11 \\
\hline & & $B 5_{d}$ & 0,724 & 5 & 0,061 & 6 \\
\hline & \multirow{2}{*}{$\begin{array}{l}\begin{array}{l}\text { Freedom of Association } \\
\text { Bargaining }\end{array} \\
\end{array}$} & $B 6_{a}$ & 0,379 & 13 & 0,049 & 11 \\
\hline & & $B 6_{a}$ & 0,394 & 12 & 0,049 & 11 \\
\hline \multirow{17}{*}{$\begin{array}{l}\text { Local } \\
\text { community }\end{array}$} & \multirow{2}{*}{ Safe and Healthy Living Conditions } & $\mathrm{Cl}_{\mathrm{a}}$ & 0,125 & 17 & 0,040 & 17 \\
\hline & & $\mathrm{Cl}_{\mathrm{b}}$ & 0,157 & 16 & 0,050 & 14 \\
\hline & \multirow[t]{2}{*}{ Secure Living Conditions } & $\mathrm{C} 2_{\mathrm{a}}$ & 0,177 & 15 & 0,069 & 4 \\
\hline & & $\mathrm{C} 2_{\mathrm{b}}$ & 0,195 & 14 & 0,071 & 2 \\
\hline & \multirow[t]{3}{*}{ Local Employment } & $\mathrm{C}_{\mathrm{a}}$ & 0,660 & 3 & 0,069 & 4 \\
\hline & & $\mathrm{C} 3_{\mathrm{b}}$ & 0,503 & 8 & 0,045 & 15 \\
\hline & & $\mathrm{C}_{\mathrm{c}}$ & 0,894 & 1 & 0,078 & 1 \\
\hline & \multirow[t]{4}{*}{ Community Engagement } & $\mathrm{Cu}_{\mathrm{a}}$ & 0,398 & 11 & 0,054 & 11 \\
\hline & & $\mathrm{C4}_{\mathrm{b}}$ & 0,317 & 13 & 0,042 & 16 \\
\hline & & $\mathrm{C4}_{\mathrm{c}}$ & 0,434 & 10 & 0,057 & 9 \\
\hline & & $\mathrm{C}_{\mathrm{d}}$ & 0,360 & 12 & 0,050 & 13 \\
\hline & \multirow[t]{3}{*}{ Access to Material Resources } & $\mathrm{CS}_{\mathrm{a}}$ & 0,593 & 5 & 0,061 & 7 \\
\hline & & $\mathrm{C} 5_{\mathrm{b}}$ & 0,623 & 4 & 0,066 & 6 \\
\hline & & $\mathrm{C}_{\mathrm{c}}$ & 0,546 & 7 & 0,057 & 9 \\
\hline & \multirow[t]{3}{*}{ Access to Immaterial Resources } & $\mathrm{Cb}_{\mathrm{a}}$ & 0,556 & 6 & 0,059 & 8 \\
\hline & & $\mathrm{C} 6_{\mathrm{b}}$ & 0,667 & 2 & 0,071 & 2 \\
\hline & & $\mathrm{Cb}_{\mathrm{c}}$ & 0,491 & 9 & 0,052 & 12 \\
\hline
\end{tabular}




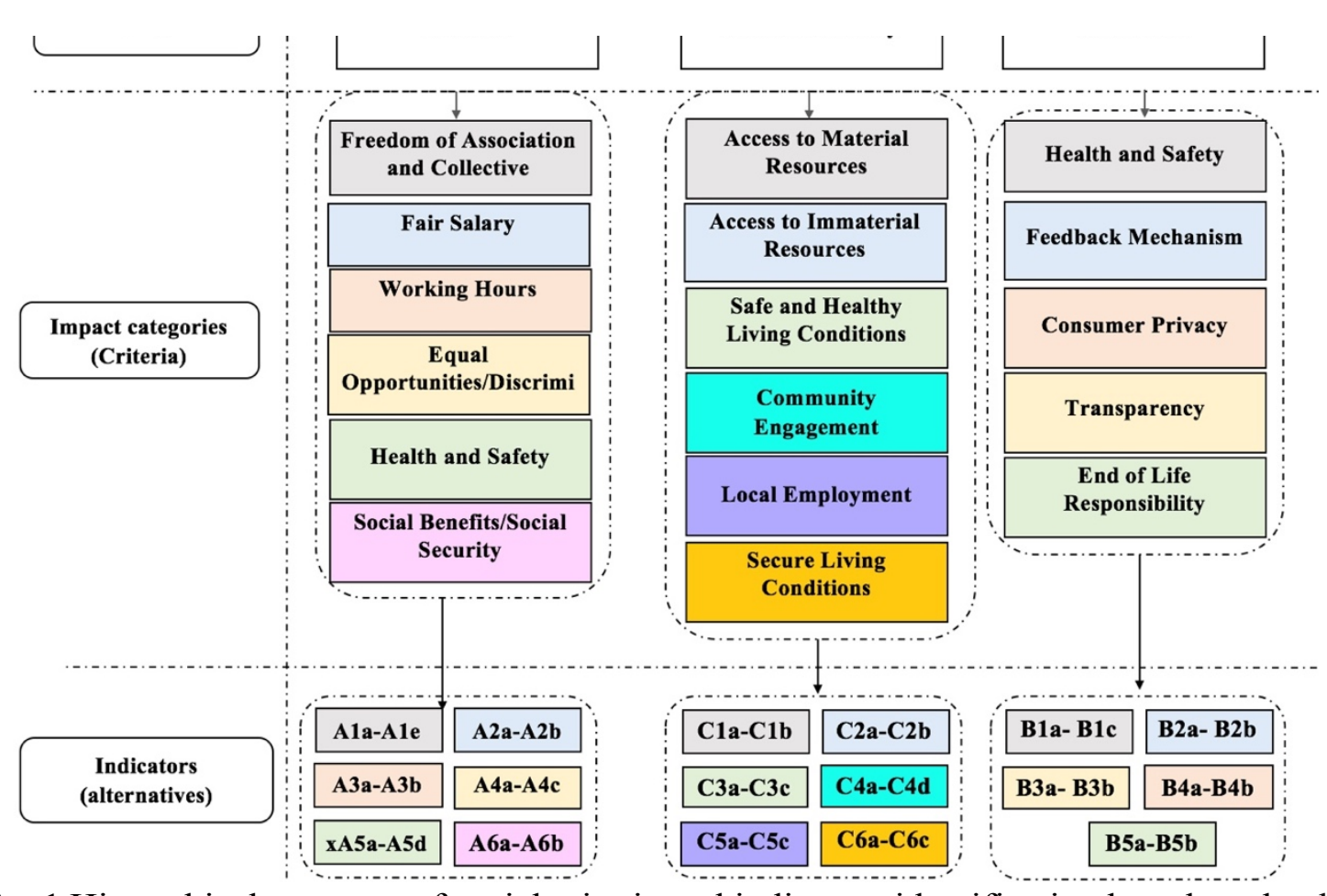

Fig. 1 Hierarchical structure of social criteria and indicators identification based on the the UNEP/SETAC (2009) guidelines. $\left(A_{i}, B_{i}\right.$, and $C_{i}$ refer to the indicators related to each category of social impact mentioned in Table 2 